efficiency. In conclusion, Prof. Bernal expressed the belief that the undifferentiated way of dealing with things which is characteristic of the scientific method, will, given good organization, build up a far better war machine than the one we have against us.

\section{The War and Nesting Birds}

THE most interesting effect of the War upon nesting birds in Great Britain has been the attraction of the black redstart (Phonicurus ochrurus gibraltariensis) to nest in the air-raid ruins of some English towns. Until the War, this was one of the rarest British nesters, although a regular winter visitor, but on the Continent where it is a familiar town bird it shows a partiality for ruins and it would be interesting if it becomes a commoner British resident in this unexpected way. In 1923 this bird was first noted nesting in Great Britain in a southern county and in 1936 it began nesting in Cambridge. In 1940 and 1941 it nested in the city area of London and a considerable number of London Natural History Society observers watched the birds. Another influence upon nesting birds has been the military disturbance of many coastal and rural haunts, the felling of woods and the draining of marshland. Another rare British nester, the black-necked grebe (Podiceps nigricollis nigricollis), was under observation by the Merseyside Naturalists' Association this year at a new nesting site at Abbot's Moss, the third it has used in Cheshire. In Anglesey there was a considerable increase in the number of roseate terns nesting at Llandwyn island, where between sixty and seventy pairs nested this year with Sandwich terns, etc., and new terneries, possibly an overflow of this species, were made at Malldraeth Point and on Ynys Ferrig rocks in Rhosneigr Bay. The kite has, however, maintained its nesting haunt in the valleys of mid-Wales and the black guillemot its recent habitat on the Cumberland cliffs at St. Bees Head.

\section{The British Association}

The report of the British Association for 1942 (Vol. 2, No. 6) is now available (price 5s.), and contains the full text of the papers given at the conference on European agriculture held by the Division for the Social and International Relations of Science in London during Mareh 20-21, 1942. Problems in postwar reconstruction was the subject of discussion at the conference, the papers falling into four main sections: measures for reconstruction, economic and kindred problems, the future betterment of European farming and problems of peasant farming. The contributors, many of whom came from occupied countries and represented very different types of farming, were remarkably in agreement as to the causes of pre-war agricultural problems and the main lines upon which future reconstruction should be based, namely, the development of small-scale peasant farming, concentrating primarily on livestock, fruit and vegetable production in order to raise the standard of living and nutrition.

In addition, the report contains an article by Sir Henry Lyons on the work of the International Research Council (now the International Council of Scientific Unions) which will be of special interest to those concermed with the possibility of increasing collaboration in science through some form of standing organization, and an account of the peace-time activities of the British Association by its president, Sir Richard Gregory.

\section{The Study of Soils}

The Cantor lectures delivered at the Royal Society of Arts by Dr. B. A. Keen in January and February on soil physics, soil cultivation, and cultivation and crop yields have been published in the Society's Journal $(40,545 ; 1942)$. The study of soil physics is relatively new, and only within the last twenty or thirty years has this side of agricultural practice been placed on a sound theoretical basis, The substitution of the pore-space theory in place of the capillary-tube hypothesis as an explanation of the water relations within the soil has, for example, led indirectly to improvements in certain practices in irrigation areas and in land drainage. The effectiveness of different types of cultivation and the influence of weather on the formation of tilth can now be measured by studying the resulting soil structure, and both the design, performance and use of implements can accordingly be put on a more scientific basis. As regards the effect of cultivation on crop yield, the traditional views held in Great Britain are called in question. Experiments on certain soils have shown no special benefits to the crop from additional or increased depth of cultivation, and since cheap labour is no longer available and every mechanized operation costs fuel and oil, a plea is made for similar investigations to be carried out in widely different districts, so that reliable information of a more general nature on such an important economic question may be forthcoming.

\section{Canadian Water Supplies}

Erght years ago the Canadian Department of Mines and Reservoirs began a survey of all the water supplies in Canada, with the view of determining the mineral and other content of the industrial and domestic water of the Dominion. The final results of this survey are now published in "Industrial Waters of Canada", by H. A. Leverin (Ottawa : King's Printer. Pp. 112. 25 cents). The investigation involved the determination of suspended matter, silica, iron, calcium, magnesium, sulphate, alkalis, potassium, bicarbonate, free carbonic acid, chloride, nitrate, oxygen, hydrogen-ion and colour. The report discusses the origin and distribution of these impurities and their importance in many industrial processes. It appears that distilled water is necessary not only in the manufacture of chemicals or drugs but also in the manufacture of ice, storage batteries, yeast, aerated waters and the plating of mirrors. In the paper and pulp industry, in the making of such varied commodities as textiles, soap and ice, and in brewing, distilling, baking, tanning, canning, etc., the nature and amount of the impurities are of much significance. The processes used in the investigations are fully described, and the publication contains tabulated analyses of surface and civic water supplies and maps showing the hardness of town water supplies throughout the Dominion.

\section{Tuberculosis in Ei Salvador}

THE March issue of the Boletin de la Oficina Sanitaria Panamericana contains an interesting paper by Dr. Rafael Vega Gomez, head of the Tuberculosis Department and ex-director of health, EI Salvador, on the control of tuberculosis in his country. The campaign against the disease began in 1928 with the foundation of a National Tuberculosis Sanitorium, in which the number of beds has risen from 30 to 105 . Previously the only accommodation for tuberculosis 
were some rooms in the Hospital Rosales of El Salva. dor. In 1931 the local Red Cross opened the first public dispensary and founded the National Anti-tuberculosis League. Five years later another dispensary was opened at Santa Ana. In 1939 the director of health created a Department of Tuberculosis and in 1940 opened a new dispensary where 14,000 examinations were made and 93 per cent of the contacts were investigated, while 5,000 homes were visited. In 1938 the first census was taken to determine the amount of infections among school children in the capital ; 4,151 were examined. The Montoux and Pirquet tests were found to be positive in 32.8 per cent of the five to six year olds, and in 62 per cent of those aged 14-15. Similar results were obtained in Santa Ana in 1939. Of 12,000 apparently healthy persons at El Salvador in a population of 100,000 , 1.42 per cent showed signs of active tuberculosis. Recent figures showed a distribution of 22 per cent, 64 per cent and 14 per cent among the minimal, moderate and advanced lesions respectively, which are very encouraging figures compared with those of 1932, when about 72 per cent of the cases showed advanced lesions.

\section{Suppressing High-Frequency Disturbances from Telephone Apparatus}

IN an article by M. E. Krom (Bell Lab. Rec., 20, No. 10, June 1942) it is pointed out that disturbances such as those arising from the opening of the contacts of a telephone dial may be represented by an infinite number of alternating currents extending upwards through the entire radio spectrum. Disturbances of this type may reach receivers by direct radiation, by coupling between the telephone line and receiving antenna, or by secondary coupling via some outside electrical system such as a power line. Two general types of suppression devices are available to limit noise influence. One, located at the source, tends to reduce the radio-frequency voltages developed ; the other-usually remote from the source -is functionally a low pass filter. The former type most commonly consists of a small inductance and capacitance connected across the dial contacts. The inductance prevents too rapid a build-up of current as the contacts close whilst the capacitance reduces the voltage on the telephone line as they open.

The filter action results in the voltage increasing slowly as the contacts open, instead of producing a series of high-frequency surges, and $40-55 \mathrm{db}$. suppression is obtained. Another type of filter similar in action but of different characteristics, is used to suppress radio-frequency voltages from teleprinters and affords some $50-60 \mathrm{db}$. suppression over the range of from $200-30,000 \mathrm{kc}$. The disturbances from power plant associated with telephone equipment are usually effectively suppressed $(20-25 \mathrm{db}$.) by simple condensers. Where the individual sources of noise are numerous the second general type of device-the low pass filter-is used, and it may consist of an inductance connected in series with each side of the line, the outgoing ends of which are terminated by a condenser connected to earth. It is desirable that inductive elements used in radio filters have a high effective resistance over a wide band of frequencies instead of a peaked impedance at the resonant frequency.

\section{Man-Made Radio Interference}

AN article by R. A. Shetzline (Bell Lab. Rec., 20, No. 10, June 1942) reviews the factors involved in this increasingly important subject. Opening with a brief reference to the multi-frequency disturbances caused by the operation of a relay or switch, the author cites an example of a telephone line and an adjacent power line as a source of interference to a nearby radio receiver. Attention is directed to the signal-to-noise ratio of a receiver as the criterion of its performance, and it is shown how this ratio is dependent on the field intensity of the received radio signal and on the effectiveness of the antenna, the latter being a function of the effective height of the antenna and the impedance relations between antenna and receiver.

Expressions are evolved from which it becomes apparent that the best radio reception is obtained when the field intensity, antenna efficiency, line coupling loss and the attenuation along the line are greatest; the latter depends upon whether the line be cable or open wire. Interference by direct radia. tion becomes of importance only when the source is close to the antenna or on the same premises as the receiver. Experience has shown that in many instances noisy reception reports arise only when distant stations are sought. With field strengths of reasonable values, and with suitable antenna circuits, simple preventive measures should mitigate the annoyance caused to radio listeners by telephone apparatus.

\section{The Night Sky in September}

The moon is new on September 10d. 15h. 53m. U.T. and full on September 24d. 14h. 34m. The following conjunctions will occur during the month : Sept. 2 d. $20 \mathrm{~h}$., Saturn in conjunction with the moon, Saturn $3^{\circ}$ N. ; Sept. 6d. 00h., Jupiter in conjunction with the moon, Jupiter $4^{\circ}$ N. ; Sept. 9d. 05h., Venus in conjunction with the moon, Venus $2^{\circ}$ N. ; Sept. 9d. 15h., Venus in conjunction with Regulus, Venus $0 \cdot 7^{\circ}$ N. ; Sept. 12d. 15h., Mercury in conjunction with the moon, Mercury $6^{\circ} \mathrm{S}$.; Sept. 30d. 05h., Saturn in conjunction with the moon, Saturn $3^{\circ} \mathrm{N}$. Mercury, in greatest elongation, $27^{\circ}$, on Sept. 15, is an evening star and unfavourably placed for observation for northern observers. Venus is a morning star, and Jupiter in Gemini is well placed for observation in the morning. Saturn and Uranus are not very far from Aldebaran and appear in the east before midnight. No occultations of any bright stars will occur during the month. The longer evenings provide an opportunity for seeing many interesting sights such as the Pleiades, the variable star Algol, the Great Nebula of Andromeda close to the star $\vee$ Andromedæ, and other objects of interest.

There will be a partial eclipse of the sun on Sept. 10, visible at Greenwich. The circumstances of the eclipse at Greenwich are as follows :

$$
\begin{array}{cccc}
\text { Magnitude } & \text { Eclipse begins } & \text { Greatest phase } & \text { Eclipse ends } \\
0.33 & 15 \mathrm{~h} .24 \mathrm{~m} . & 16 \mathrm{~h} .17 \mathrm{~m} . & 17 \mathrm{~h} .07 \mathrm{~m} .
\end{array}
$$

\section{Announcements}

Sir Henry Dale, who was recently appointed a member of the Governing Body of the Lister Institute of Preventive Medicine, has been elected by the Board as its chairman.

An open meeting of the Association of Scientific Workers will be held on September 4 at 7 p.m. at the Caxton Hall, London, S.W.l, to discuss and support proposals for a Central Scientific and Technical Board. The speakers will include Lord Strabolgi. 